\title{
Differential activation energy and NBO interaction approaches to torquoselectivity and its dependence on the conformational profile of the substituent
}

\author{
Veejendra K. Yadav* \\ Department of Chemistry, Indian Institute of Technology Kanpur, Kanpur 208016, India \\ vijendra@iitk.ac.in
}

\begin{abstract}
The torquoselectivity of ring opening of 3- $\mathrm{CF}_{3}-\mathrm{cyclobutene,} 3-\mathrm{CHF}_{2}-\mathrm{cyclobutene}, 3-\mathrm{CH}_{2} \mathrm{~F}-$ cyclobutene, 3- $\mathrm{CF}_{3}-0 x$ etene and perfluoro-3- $\mathrm{CH}_{3}-\mathrm{Cyclobutene}$ have been studied at the MP2/cc-pVTZ level of theory and the results analysed by using the differential activation energy approach and also differential NBO interactions of the breaking ring bond with the substituent bonds. The outward or inward ring opening that has lower activation energy in the differential activation energy approach or larger interaction in the differential NBO interaction approach constitutes the preferred mode. The predictions from the two approaches are largely found to be contradicting each other, specifically when the substituent is electron-deficient. The $\mathrm{CHF}_{2}$ and $\mathrm{CH}_{2} \mathrm{~F}$ substituents on cyclobutene and oxetene can adopt three distinct conformations with respect to the cleaving ring bond. It has been discovered that each conformer exhibits a distinct level of torquoselectivity and some may even contribute to the overall selectivity substantially. The conformational profile of the substituent, therefore, is recommended to be taken into account in any serious treatment of the subject. The experimental torquoselectivity, if otherwise, is a likely consequence of secondary reactions, specifically equilibration through reaction reversal while honouring the relative thermodynamic stabilities of the ring opened products.
\end{abstract}

Keywords: torquoselectivity, 3-fluoromethylcyclobutenes, 2-fluoromethyloxetenes, 3methylperfluorocyclobutene, differential activation energy, differential NBO interaction, conformational effects

\section{Introduction}

The ring opening of cyclobutene proceeds in conrotatory fashion under thermal conditions to form 1,3-butadiene. ${ }^{1}$ The generally outward $(\mathbf{1} \rightarrow \mathbf{2})$ and inward $(\mathbf{3} \rightarrow \mathbf{4})$ rotations of, respectively, electronrich and electron-withdrawing substituents are controlled by the phenomenon called torquoselectivity. It is typically predicted by estimating the transition structure barriers and the lower barrier pathway constitutes the preferred mode of ring opening. ${ }^{2}$ 


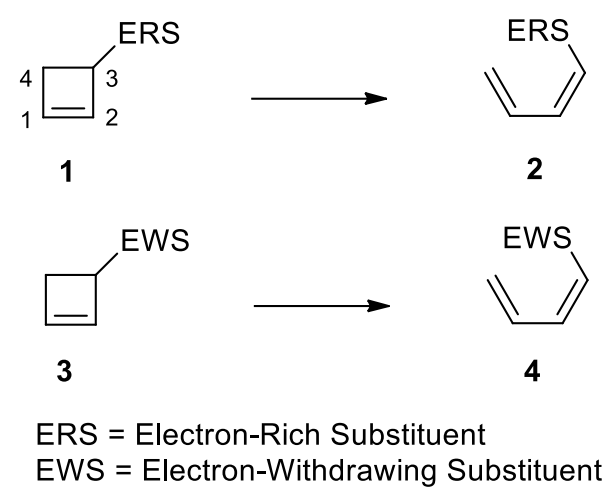

In 2001, Murakami and co-workers observed 83:17 kinetic distribution of the inward and outward opened products on heating 1-octyl-3-dimethylphenylsilylcyclobutene 5 at $140{ }^{\circ} \mathrm{C}$ in $m$-xylene for 1 hour. ${ }^{3}$ Likewise, the reaction of 1-dimethylphenylmethy-3-trimethysilylcyclobutene 8 at $140{ }^{\circ} \mathrm{C}$ in $\mathrm{m}$ xylene for 9 hours generated a 69:31 mixture of the inward and outward opened products, respectively. The preference for inward rotation of the silyl substituent was ascribed to a favorable overlap of the low-lying $\sigma^{*}$ orbitals of the silyl substituent with the occupied $\sigma_{\text {сзс4 }}$ orbital of the breaking bond in the corresponding transition state (TS) structure. The differential activation energy approach predicts the inward opening of 3-trimethylsilylcyclobutene favored over outward opening by $2.0 \mathrm{kcal} / \mathrm{mol}$ at M06-2X/6-31G(d) level of theory. ${ }^{4}$ The inward and outward opening reactions of 3trimethylsilylcyclobutene are exergonic by, respectively, 6.7 and $9.2 \mathrm{kcal} / \mathrm{mol}$. The interaction $\sigma_{\mathrm{c} 3{ }_{4} 4} \rightarrow$ $\sigma^{*}{ }_{\text {csi }}$ was estimated at $11.3 \mathrm{kcal} / \mathrm{mol}$ in the inward TS structure as compared to only $5.0 \mathrm{kcal} / \mathrm{mol}$ in the outward TS structure.
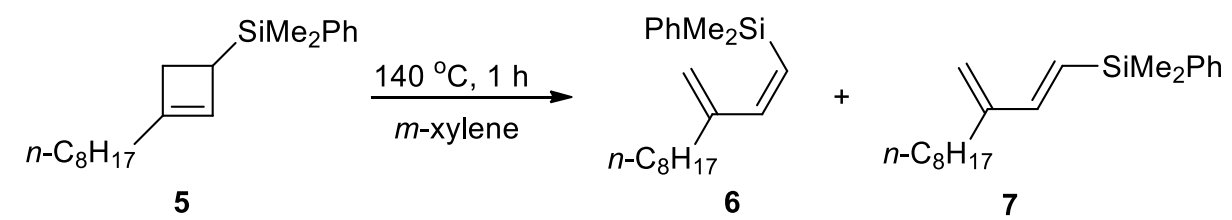

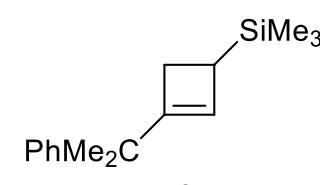

8

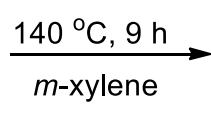

$\frac{140^{\circ} \mathrm{C}, 9 \mathrm{~h}}{m \text {-xylene }}$

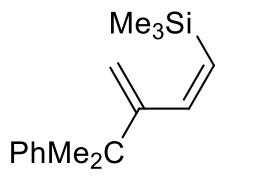

9

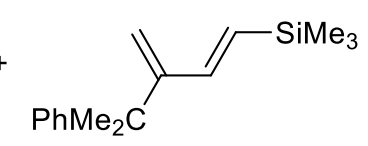

10

In 2003, Houk observed that the filled orbital of a donor substituent experienced closed-shell repulsion upon inward rotation and, therefore, it preferred to rotate outward. In contrast, a vacant acceptor orbital on the substituent was predicted for inward rotation to maximize orbital interaction between the filled orbital of the breaking bond and the vacant orbital of the substituent in the transition state. ${ }^{5}$ 
Since the electronic as well as steric effects are well embedded in the TS structure, focus on closedshell repulsion separate from the differential activation energy is unwarranted.

In application of the differential activation energy approach in its purest form, calculations at B3LYP/6$31 \mathrm{G}(\mathrm{d})$ level predicted outward openings of 3- $\mathrm{CF}_{3^{-}}, 3-\mathrm{CF}_{2} \mathrm{H}$ - and 3- $\mathrm{CH}_{2} \mathrm{~F}-\mathrm{cyclobutenes}$ favored over the corresponding inward openings by $2.3,0.3$ and $2.0 \mathrm{kcal} / \mathrm{mol}$, respectively. ${ }^{5}$ However, in partial departure, activation energies calculated at M06-2X/6-311+G(2d,p) level by Barquera-Lozada favored inward opening of $3-\mathrm{CF}_{2} \mathrm{H}-\mathrm{cyclobutene}$ by $1.5 \mathrm{kcal} / \mathrm{mol} .{ }^{6}$ Dolbier and co-workers have experimentally discovered $3-\mathrm{CF}_{3}$-cyclobutene to open predominantly outward. ${ }^{7}$ Interestingly, the relative concentration of the inward product was found to significantly rise at the expense of the outward product on raising the reaction temperature. For instance, the ratio of the outward and inward products changed from $43.5: 1$ at $56.5^{\circ} \mathrm{C}$ to $13.2: 1$ at $188.5^{\circ} \mathrm{C}$ while the outward product was more stable than inward product with standard enthalpy difference of $2.5 \pm 0.4 \mathrm{kcal} / \mathrm{mol}$. The transformation of the outward opened product to the inward product on rise in reaction temperature requires explanation because it cannot be due to double bond isomerization for the requirement of significantly high activation energy.

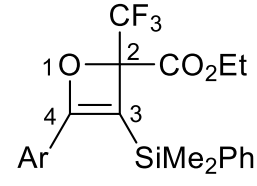

11

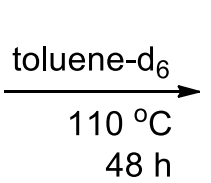

$48 \mathrm{~h}$

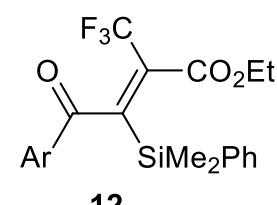

12

In 2011, Mikami studied the ring opening of 2- $\mathrm{CO}_{2} \mathrm{Et}-2-\mathrm{CF}_{3}-3$-dimethylphenylsilyl-4-aryloxetene 11 under thermal conditions (toluene- $\mathrm{d}_{6}, 110^{\circ} \mathrm{C}, 48 \mathrm{~h}$ ) and observed its quantitative transformation to the product 12 with exclusive inward rotation of the $\mathrm{CF}_{3}$ group. ${ }^{8} \mathrm{He}$ also observed predominance of inward rotation of the $\mathrm{CF}_{3}$ group on ring opening of the closely related 2- $\mathrm{CO}_{2} \mathrm{Et}^{-2}-\mathrm{CF}_{3}-3-$ methyl-4phenyloxetene by a margin of $81: 19$ at $70{ }^{\circ} \mathrm{C}$ and $77: 23$ at $100{ }^{\circ} \mathrm{C} .{ }^{9}$ The rise in the concentration of the outward product on rise in reaction temperature must be noted. The results were explained by the $\sigma_{c-o} \rightarrow \sigma_{c-F} *$ type NBO interaction that was larger in the TS for inward rotation of the $\mathrm{CF}_{3}$ group than outward rotation. Going by the recommendations of the original differential activation energy approach, $\mathrm{CF}_{3}$ group appears more electron-deficient than $\mathrm{CO}_{2} \mathrm{Et}$. It will be interesting to explore just 2- $\mathrm{CF}_{3}$-oxetene to assess the otherwise unperturbed electronic effects of the $\mathrm{CF}_{3}$ group in regard to both the differential activation barrier and NBO interactions.

In 2015, Houk and Mikami concluded from M06-2X/6-31+G(d,p) level calculations that the torquoselectivies of a series of mono-, di-, and trifluoromethylcyclobutenes and also oxetenes result 
from the interplay of favorable orbital interactions and closed-shell repulsions. ${ }^{10}$ The authors articulated that when the substituent rotated inward, there was a favorable interaction between the breaking $\sigma_{\mathrm{C}-\mathrm{O}}$ bond and $\sigma^{*}{ }_{\mathrm{C}-\mathrm{F}}$ orbital $\left(\sigma_{\mathrm{C}-\mathrm{O}} \rightarrow \sigma^{*}{ }_{\mathrm{C}-\mathrm{F}}\right)$ of the fluoromethyl group in fluoromethyloxetenes. Also, the preference for inward rotation of a fluoromethyl group decreased because the closed-shell repulsion ${ }^{\mathrm{n}} \mathrm{F}-\sigma_{\mathrm{C}-\mathrm{O}}$ competed with $\sigma_{\mathrm{C}-\mathrm{o}} \rightarrow \sigma_{\mathrm{C}-\mathrm{F}}{ }^{*}$ interaction. The closed-shell repulsion arises when the distance between the oxygen and fluorine is less than the sum of their van der Waals radii. The attempt to first amalgamate the differential activation barrier with NBO interaction to lend additional support to the former from the latter and then turning completely to the NBO interaction alone is clearly apparent.

Like the interaction $\sigma_{\mathrm{C}-\mathrm{O}} \rightarrow \sigma_{\mathrm{C}-\mathrm{F}} *$ in oxetenes, the interaction $\sigma_{\mathrm{C}-\mathrm{C}} \rightarrow \sigma_{\mathrm{C}-\mathrm{F}} *$ may also be expected in the conrotatory ring openings of 3-fluoroalkyl-substituted cyclobutenes such as $3-\mathrm{CF}_{3^{-}}, 3-\mathrm{CHF}_{2^{-}}$and 3$\mathrm{CH}_{2} \mathrm{~F}$-cyclobutenes. An investigation into this and also whether or not the findings differed from those for the corresponding oxetene systems was, therefore, felt necessary. It also provides an opportunity to study, for the first time, the effects of conformational changes of the $\mathrm{CHF}_{2}$ and $\mathrm{CH}_{2} \mathrm{~F}$ substituents in respect of the breaking cyclobutene bond. The orbital interaction is the greatest when the two bonds are antiperiplanar. ${ }^{11}$ Substituents' conformational effects on torquoselectivity have not been investigated prior to this report.

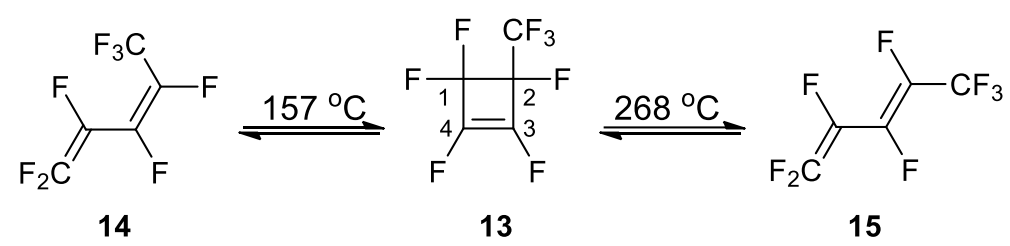

In 1986, Dolbier reported that perfluoro-3-methylcyclobutene 13 furnished only 14, the product of inward rotation of the $\mathrm{CF}_{3}$ group, when the ring opening reaction was conducted at $157^{\circ} \mathrm{C}$. However, the product profile changed to exclusively form 15 , the product of outward rotation of the $\mathrm{CF}_{3}$ group, on conducting the reaction at $268^{\circ} \mathrm{C} .{ }^{12}$ The switch over from (Z)-14 at lower temperature to $(E)-\mathbf{1 4}$ at higher temperature needs to be understood.

Computational Methodology: We have carried out quantum chemical calculations at MP2/cc-pVTZ level of theory using Gaussian $09^{13}$ to elucidate the electronic controls of NBO interactions on the torquoselectivities of 3-fluoromethylcyclobutenes, 2-fluoromethyloxetenes and perfluoro-3-methylcyclobutene. Optimized structures were verified as minima or first order saddle points on the potential energy surfaces by harmonic vibrational frequency analysis. See the Supporting Information (SI) for the geometrical coordinates of all the structures in the ground as well as in the transition state structures. 


\section{Results and Discussion}

The activation free energies of the ring openings of $3-\mathrm{CF}_{3^{-}}, 3-\mathrm{CF}_{2} \mathrm{H}-$ and $3-\mathrm{CH}_{2} \mathrm{~F}-\mathrm{cyclobuetenes}$ are collected in Table 1. For the substituents $\mathrm{CF}_{2} \mathrm{H}$ and $\mathrm{CH}_{2} \mathrm{~F}$, three different conformers were considered. The torsion angle of the $\sigma_{C-H}$ bond in the substituent $\mathrm{CF}_{2} \mathrm{H}$ with the $\sigma_{C 3-C 4}$ bond of cyclobutene was varied to have three distinct conformers. Likewise, the torsion angle of the $\sigma_{c-F}$ bond in the substituent $\mathrm{CH}_{2} \mathrm{~F}$ with the $\sigma_{\mathrm{C} 3-\mathrm{C} 4}$ bond of cyclobutene was varied. This exercise was taken to study the conformational effects on torquoselectivity. Some of the higher lying conformers are likely to be closer to the transition state structure and, hence, react faster than other conformers. Further, since the NBO interactions in the TS structures for different conformers are expected to be different in reference to the stereoelectronic effects ${ }^{11}$, the torquoselectivity may alter completely or, in the least, its level may be affected.

Table 1. Gibbs free energies of activation $\left(\Delta G^{\ddagger}\right), \mathrm{kcal} / \mathrm{mol}$, obtained at $298.15 \mathrm{~K}$ and $1 \mathrm{~atm}$ pressure for the ring openings of 3-fluoromethylcyclobutenes as compared to 3-methylcyclobutene. The enthalpy changes ( $\Delta G_{\text {product }}$ - $\Delta G_{\text {reactant }}$ are given in the parentheses. $\Delta \Delta G^{\ddagger}=\Delta G^{\ddagger}{ }_{\text {outward }}-\Delta G^{\ddagger}$ inward

\begin{tabular}{|c|c|c|c|c|}
\hline Entry & Substituent & $\Delta \boldsymbol{G}^{\ddagger}{ }_{\text {outward }}$ & $\Delta \boldsymbol{G}_{\text {inward }}^{\ddagger}$ & $\Delta \Delta \mathbf{G}^{\ddagger}$ \\
\hline 1 & $\mathrm{CF}_{3}$ & $33.2(-5.6)$ & $36.3(-1.8)$ & -3.1 \\
\hline 2 & $\mathrm{CHF}_{\mathbf{2}}{ }^{\mathrm{a}}$ & $32.8(-5.4)$ & $33.2(-5.0)$ & -0.4 \\
\hline 3 & $\mathrm{CHF}_{\mathbf{2}}{ }^{\mathrm{b}}$ & $32.9(-6.2)$ & $36.1(-2.8)$ & -3.2 \\
\hline 4 & $\mathrm{CHF}_{2}{ }^{\mathrm{c}}$ & $31.9(-6.3)$ & $35.4(-2.0)$ & -3.5 \\
\hline 5 & $\mathrm{CH}_{2} \mathrm{~F}^{\mathrm{d}}$ & $31.4(-7.1)$ & $34.5(-5.7)$ & -3.1 \\
\hline 6 & $\mathrm{CH}_{2} \mathrm{~F}^{\mathrm{e}}$ & $31.3(-7.2)$ & $32.9(-6.3)$ & -1.6 \\
\hline 7 & $\mathrm{CH}_{2} \mathbf{F}^{\mathrm{f}}$ & $30.6(-7.6)$ & $36.5(-3.5)$ & -5.9 \\
\hline
\end{tabular}

${ }^{a}$ Torsion angle $\mathrm{C} 4-\mathrm{C} 3-\mathrm{C}-\mathrm{H}=-47.0 .{ }^{\mathrm{b}}$ Torsion angle $\mathrm{C} 4-\mathrm{C} 3-\mathrm{C}-\mathrm{H}=70.7 .{ }^{\mathrm{C}}$ Torsion angle $\mathrm{C} 4-\mathrm{C} 3-\mathrm{C}-\mathrm{H}=-169.0$.

${ }^{\mathrm{d}}$ Torsion angle $\mathrm{C} 4-\mathrm{C} 3-\mathrm{C}-\mathrm{F}=72.6$. ${ }^{\mathrm{e}}$ Torsion angle $\mathrm{C} 4-\mathrm{C} 3-\mathrm{C}-\mathrm{F}=-167.6 .{ }^{\mathrm{f}}$ Torsion angle C4-C3-C-F $=-49.4$

A bird's eye view of the activation energy data demonstrates that all the three substrates must open predominantly outwards. However, two entries are noteworthy. First, the most stable of the three conformers at entry 2 shows the lowest level of selectivity with 2:1 kinetic distribution of the products in favor of outward opening. The other two conformers must exclusively form the outward opened product for $>3.0 \mathrm{kcal} / \mathrm{mol}$ differential activation free energies. Among the conformers of the substrates bearing the $\mathrm{CH}_{2} \mathrm{~F}$ substituent, all but the conformer at entry 6 are expected to exclusively open outwards. The conformer at entry 6 , which has $\sigma_{\mathrm{C} 3-C 4_{4}}$ and $\sigma_{\mathrm{c}-\mathrm{F}}$ nearly antiperiplanar, is comparatively less selective as it can generate $6-7 \%$ of the inward product also. 
Table 2. NBO interactions $(\mathrm{kcal} / \mathrm{mol})$ in the TSs for the ring opening of 3-fluoromethycyclobutenes. The values in the parentheses are for the inward opening TSs.

\begin{tabular}{|c|c|c|c|c|}
\hline Substrate & $\pi_{\mathrm{c} 1 \mathrm{C} 2} \rightarrow \sigma^{*}{ }_{\mathrm{c} 3 \mathrm{C} 4}$ & $\sigma_{\mathrm{C} 3 \mathrm{C} 4} \rightarrow \pi^{*}{ }_{\mathrm{c} 1 \mathrm{C} 2}$ & $\sigma_{\mathrm{C} 3 \mathrm{C} 4} \rightarrow \sigma_{\mathrm{C}-\mathrm{F} / \mathrm{H}}$ & $\sigma_{C-\mathrm{F} / \mathrm{H}} \rightarrow \sigma^{*}{ }_{\mathrm{C3C}}$ \\
\hline CF3 & $64(71)$ & $78(84)$ & $11(21)$ & $1.9(1.7)$ \\
\hline $\mathrm{CHF}_{2}{ }^{\mathrm{a}}$ & $62(64)$ & $81(83)$ & $9(25)$ & $6.4(2.8)$ \\
\hline $\mathrm{CHF2}^{\mathrm{b}}$ & $63(73)$ & $77(84)$ & $10(18)$ & $2.5(2.1)$ \\
\hline $\mathrm{CHF}_{2}{ }^{\mathrm{c}}$ & $61(69)$ & $81(85)$ & $9(16)$ & $6.4(4.7)$ \\
\hline $\mathrm{CH}_{2} \mathrm{~F}^{\mathrm{d}}$ & $55(62)$ & $78(85)$ & 7 (19) & $9.5(4.0)$ \\
\hline $\mathrm{CH}_{2} \mathrm{~F}^{\mathrm{e}}$ & $55(64)$ & $78(81)$ & $7(23)$ & 9.5 (3.2) \\
\hline $\mathrm{CH}_{2} \mathrm{~F}^{\mathrm{f}}$ & $61(68)$ & $80(86)$ & $7(12)$ & $10(7.3)$ \\
\hline
\end{tabular}

${ }^{a}$ Torsion angle $\mathrm{C} 4-\mathrm{C} 3-\mathrm{C}-\mathrm{H}=-47.0 .{ }^{\mathrm{b}}$ Torsion angle $\mathrm{C} 4-\mathrm{C} 3-\mathrm{C}-\mathrm{H}=70.7 .{ }^{\mathrm{c}}$ Torsion angle $\mathrm{C} 4-\mathrm{C} 3-\mathrm{C}-\mathrm{H}=-169.0$.

${ }^{\mathrm{d}}$ Torsion angle $\mathrm{C} 4-\mathrm{C} 3-\mathrm{C}-\mathrm{F}=72.6$. ${ }^{\mathrm{e}}$ Torsion angle $\mathrm{C} 4-\mathrm{C} 3-\mathrm{C}-\mathrm{F}=-167.6 .{ }^{\mathrm{f}}$ Torsion angle $\mathrm{C} 4-\mathrm{C} 3-\mathrm{C}-\mathrm{F}=-49.4$.

Now, we switch to looking at the NBO interactions collected in Table 2 . The interactions $\sigma_{\mathrm{C3C4}} \rightarrow \sigma^{*}{ }_{\mathrm{c}}$ $F / H$ and $\sigma_{C-F / H} \rightarrow \sigma_{C 3 C 4}^{*}$ are to be taken together because both weaken the $\sigma_{C 3 C 4}$ bond. The $\sigma_{C-F / H}$ refers to all the $\sigma_{\mathrm{C}-\mathrm{H}}$ and $\sigma_{\mathrm{C}-\mathrm{F}}$ bonds in the substituent group. On account of the significantly higher interaction in the inward mode of opening compared to the corresponding outward opening, all the three substrates are predicted to cause inward opening, which clearly contradicts the prediction made by the differential activation energy approach. The difference of the interactions in the TS structures for inward and outward openings of the least stable of the three conformers at the last entry is the least $(2.3 \mathrm{kcal} / \mathrm{mol})$ and, hence, the level of torquoselectivity may somewhat be compromised.

Suitable orbital interaction is more important than steric and other interactions, so much so that conformers facing severest of steric interactions are known to react in exclusive preference to the all relaxed (the most stable) conformer. ${ }^{14}$ We subscribe to the NBO interaction argument for the prediction of torquoselectivity of ring opening of substituted cyclobutenes and oxetenes. We present the results herein.

$3-\mathrm{CF}_{3}$-cyclobutene has been reported to open exclusively outward on heating at $146-186^{\circ} \mathrm{C}$ in the gas phase at 3-4 mm pressure in a sealed tube. The experimental results of the ring openings of $3-\mathrm{CF}_{2} \mathrm{H}-$ and $3-\mathrm{CH}_{2} \mathrm{~F}$-cyclobutenes are not reported in the literature. Both the outward and inward opening reactions of 3-CHF - and $3-\mathrm{CH}_{2} \mathrm{~F}-\mathrm{cyclobutenes}$ are estimated to be sufficiently exergonic to discourage equilibration through reversal under mild reaction conditions. However, the inward opening of 3- $\mathrm{CF}_{3}-$ cyclobutene is only $1.8 \mathrm{kcal} / \mathrm{mol}$ exergonic in comparison to $5.6 \mathrm{kcal} / \mathrm{mol}$ for outward opening. This translates into 38.1 and $38.8 \mathrm{kcal} / \mathrm{mol}$ as the activation barriers for the ring closing reverse reactions of the inward and outward opened products, respectively. Since the barrier for the ring closing reaction of the inward opened product is only $1.8 \mathrm{kcal} / \mathrm{mol}$ higher than the corresponding ring opening 
reaction, it is likely that the two compete under the high energy conditions of the reaction while the more stable outward opened product accumulates to predominate eventually. The free energy profile of the reaction of $3-\mathrm{CF}_{3}-\mathrm{Cyclobutene}$ is given in Figure 1.

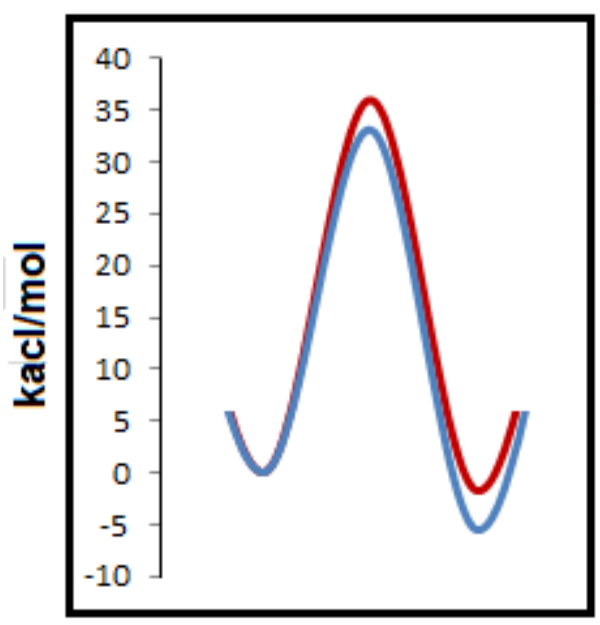

Reaction coordinate

Figure 1. Reaction profile for inward (solid red line) and outward (solid blue line) ring openings in 3-CF3cyclobutene at the MP2/cc-pVTZ level of theory

The activation free energies and enthalpy changes for the outward and inward openings of 2fluoromethyloxetenes are collected in Table 3. All the reactions are highly exergonic and, hence, equilibration by reaction reversal is unlikely. Since the activation free energy for outward rotation is generally significantly lower than that for the corresponding inward rotation, exclusive outward rotation is predicted. The conformer at entry 2 , however, deserves special comment. This conformer is the most stable among three conformers. The differential activation free energy is only $0.7 \mathrm{kcal} / \mathrm{mol}$ and, hence, it will be expected to generate $20-25 \%$ of the inward product as well. The reaction profiles for the outward and inward openings of $3-\mathrm{CF}_{3}-\mathrm{Cyclobutene}$ is given in Figure 2 .

Table 3. Gibbs free energies of activation $\left(\Delta G^{\ddagger}\right), \mathrm{kcal} / \mathrm{mol}$, obtained at $298.15 \mathrm{~K}$ and 1 atm pressure for the ring openings of 2-fluoromethyloxetenes. The enthalpy changes ( $\Delta G_{\text {product }}-\Delta G_{\text {reactant }}$ ) are given in the parentheses. $\Delta \Delta G^{\ddagger}=\Delta G^{\ddagger}{ }_{\text {outward }}-\Delta G^{\ddagger}$ inward

\begin{tabular}{|c|c|c|c|c|}
\hline Entry & Substituent & $\Delta \boldsymbol{G}_{\text {outward }}^{\ddagger}$ & $\Delta \boldsymbol{G}_{\text {inward }}^{\ddagger}$ & $\Delta \Delta \mathbf{G}^{\ddagger}$ \\
\hline 1 & $\mathrm{CF}_{3}$ & $28.0(-25.7)$ & $30.8(-20.1)$ & -2.8 \\
\hline 2 & $\mathrm{CHF}_{2}^{\mathrm{a}}$ & $28.5(-24.3)$ & $29.2(-23.1)$ & -0.7 \\
\hline 3 & $\mathrm{CHF}_{2}{ }^{\mathrm{b}}$ & $27.2(-25.5)$ & $29.9(-24.3)$ & -2.7 \\
\hline 4 & $\mathrm{CHF}_{2}{ }^{\mathrm{c}}$ & $26.5(-26.6)$ & $30.8(-19.5)$ & -4.3 \\
\hline 5 & $\mathbf{C H}_{2} \mathbf{F}^{d}$ & $24.7(-24.3)$ & $31.0(-24.9)$ & -6.3 \\
\hline
\end{tabular}




$\begin{array}{lllll}6 & \mathrm{CH}_{2} \mathrm{~F}^{\mathrm{e}} & 24.2(-24.8) & 28.5(-25.5) & -4.3 \\ 7 & \mathrm{CH}_{2} \mathrm{~F}^{\mathrm{f}} & 24.2(-26.7) & 30.7(-26.0) & -6.5\end{array}$

${ }^{\mathrm{a}}$ Torsion angle $\mathrm{O} 1-\mathrm{C} 2-\mathrm{C}-\mathrm{H}=-49.1 .{ }^{\mathrm{b}}$ Torsion angle $\mathrm{O} 1-\mathrm{C} 2-\mathrm{C}-\mathrm{H}=60.6 .{ }^{\mathrm{c}}$ Torsion angle $\mathrm{O} 1-\mathrm{C} 2-\mathrm{C}-\mathrm{H}=-172.6$.

${ }^{\mathrm{d}}$ Torsion angle $\mathrm{O} 1-\mathrm{C} 2-\mathrm{C}-\mathrm{F}=74.6$. ${ }^{\mathrm{e}}$ Torsion angle $\mathrm{O} 1-\mathrm{C} 2-\mathrm{C}-\mathrm{F}=-174.7 .{ }^{\mathrm{f}}$ Torsion angle $\mathrm{O} 1-\mathrm{C} 2-\mathrm{C}-\mathrm{F}=-61.9$.

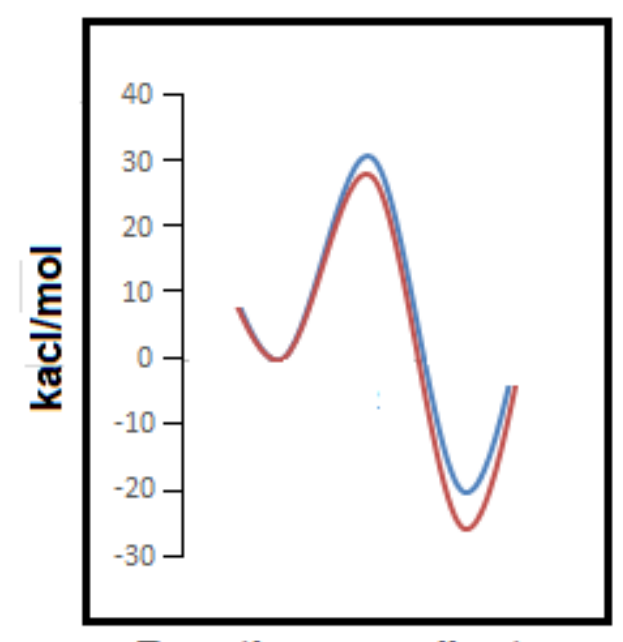

Reaction coordinate

Figure 2. Reaction profile for inward (solid blue line) and outward (solid red line) ring openings in 2trifluoromethyloxetene at the MP2/cc-pVTZ level of theory

In contrast, the NBO interactions $\sigma_{\mathrm{C}-\mathrm{O}} \rightarrow \sigma^{*}{ }_{\mathrm{C}-\mathrm{F}}$ and $\sigma_{\mathrm{C}-\mathrm{F}} \rightarrow \sigma^{*}{ }_{\mathrm{C}-\mathrm{o}}$ support inward rotation of the $\mathrm{CF}_{3}$ group because their sum is $>7.0 \mathrm{kcal} / \mathrm{mol}$ larger in the TS structure for inward over outward rotation. Though all the conformers of the $\mathrm{CHF}_{2}$ substituent are favored for inward rotation, the differential interaction decreases from 5.3 to 4.9 to $2.0 \mathrm{kcal} / \mathrm{mol}$ as one descends the Table. This could be taken for gradually reduced torquoselectivity. The story with the $\mathrm{CH}_{2} \mathrm{~F}$ substituent is different. The differential interaction is small, but in support of outward opening for the first two conformers and a mixture for the last one. Overall, 3- $\mathrm{CH}_{2} \mathrm{~F}$-cyclobutene is predicted for largely outward opening, which is the same as that predicted by differential activation energy. The NBO interactions are collected in Table 4.

Finally, we return to perfluoro-3-methylcyclobutene, which is reported to furnish only the (Z)-product from inward rotation of the $\mathrm{CF}_{3}$ group on conducting the ring opening reaction at $157^{\circ} \mathrm{C}$ and the $(E)$ product from outward rotation of the $\mathrm{CF}_{3}$ group on conducting the reaction at $268^{\circ} \mathrm{C}$. ${ }^{12}$ The activation free energies for the ring openings entailing inward and outward rotations of the $\mathrm{CF}_{3}$ group are, respectively, 38.9 and $48.1 \mathrm{kcal} / \mathrm{mol}$. Thus, the inward rotation is favored over outward rotation by $9.2 \mathrm{kcal} / \mathrm{mol}$. Both the reactions are endergonic, the enthalpy change being 7.5 and $7.9 \mathrm{kcal} / \mathrm{mol}$, respectively, and hence reversible. The activation fee energies of the ring closing reactions are, therefore, 31.4 and $40.3 \mathrm{kcal} / \mathrm{mol}$, respectively. The activation free energies are collected in Table 5. 
Table 4. NBO interactions $(\mathrm{kcal} / \mathrm{mol})$ in the TSs for the ring opening of 2 -fluoromethyloxetenes. The values in the parentheses represent interactions in the inward opening TSs.

\begin{tabular}{lllll}
\hline Substrate & $\pi_{\mathrm{C} 3 \mathrm{C} \rightarrow} \rightarrow \sigma^{*}{ }_{\mathrm{C}-\mathrm{O}}$ & $\sigma_{\mathrm{C}-\mathrm{O} \rightarrow \pi^{*}{ }_{\mathrm{C} 3 \mathrm{C} 4}}$ & $\sigma_{\mathrm{C}-\mathrm{O} \rightarrow \sigma^{*}{ }_{\mathrm{C}-\mathrm{F} / \mathrm{H}}}$ & $\sigma_{\mathrm{C}-\mathrm{F} / \mathrm{H} \rightarrow \sigma^{*}{ }_{\mathrm{C}-\mathrm{O}}}$ \\
$\mathrm{CF}_{3}$ & $72(80)$ & $53(61)$ & $2.4(10)$ & $3.0(2.6)$ \\
$\mathrm{CHF}_{2}{ }^{\mathrm{a}}$ & $70(76)$ & $54(63)$ & $1.8(12)$ & $7.9(3.0)$ \\
$\mathrm{CHF}_{2}{ }^{\mathrm{b}}$ & $70(79)$ & $54(60)$ & $1.8(10)$ & $7.9(4.6)$ \\
$\mathrm{CHF}_{2}{ }^{\mathrm{c}}$ & $74(78)$ & $57(63)$ & $1.8(8.0)$ & $12.4(8.2)$ \\
$\mathrm{CH}_{2} \mathrm{~F}^{\mathrm{d}}$ & $66(76)$ & $62(72)$ & $1.5(7.7)$ & $18(10)$ \\
$\mathrm{CH}_{2} \mathrm{~F}^{\mathrm{e}}$ & $66(71)$ & $62(59)$ & $1.5(12)$ & $18(4.9)$ \\
$\mathrm{CH}_{2} \mathrm{~F}^{\mathrm{f}}$ & $68(73)$ & $56(64)$ & $1.5(6.6)$ & $19(14)$
\end{tabular}

${ }^{a}$ Torsion angle $\mathrm{O} 1-\mathrm{C} 2-\mathrm{C}-\mathrm{H}=-49.1 .{ }^{\mathrm{b}}$ Torsion angle $\mathrm{O} 1-\mathrm{C} 2-\mathrm{C}-\mathrm{H}=60.6 .{ }^{\mathrm{c}}$ Torsion angle O1- $\mathrm{C} 2-\mathrm{C}-\mathrm{H}=-172.6$.

${ }^{\mathrm{d}}$ Torsion angle O1-C2-C-F $=74.6$. ${ }^{\mathrm{e}}$ Torsion angle $\mathrm{O} 1-\mathrm{C} 2-\mathrm{C}-\mathrm{F}=-174.7 .{ }^{\mathrm{f}}$ Torsion angle O1-C2-C-F $=-61.9$.

At the lower end of the reaction temperature $\left(157^{\circ} \mathrm{C}\right)$, only the lower energy inward opening leading to the Z-olefin and the associated ring closing reactions predominate and one notices only the Z-olefin as the product. At the higher end of the reaction temperature $\left(268^{\circ} \mathrm{C}\right)$, the higher activation energy outward ring opening pathway also becomes active and the consequent product predominates for its relatively lower reversibility due to greater thermodynamic stability.

Table 5. Gibbs free energies of activation $\left(\Delta G^{\ddagger}\right), \mathrm{kcal} / \mathrm{mol}$, obtained at $298.15 \mathrm{~K}$ and 1 atm pressure for the ring openings of perfluoro-3-methylcyclobutene 13. The enthalpy change ( $\Delta G_{\text {product }}-\Delta G_{\text {reactant }}$ ) is given in the parentheses. $\Delta \Delta G^{\ddagger}=\Delta G^{\ddagger}$ outward $-\Delta G^{\ddagger}{ }_{\text {inward }}$

\begin{tabular}{llll}
\hline Substrate & $\Delta \boldsymbol{G}^{\ddagger}{ }_{\text {outward }}$ & $\Delta \boldsymbol{G}^{\ddagger}{ }_{\text {inward }}$ & $\Delta \Delta \mathbf{G}^{\ddagger}$ \\
\hline 13 & $48.1(7.5)$ & $38.9(7.9)$ & 9.2
\end{tabular}

Table 6. NBO interactions $(\mathrm{kcal} / \mathrm{mol})$ in the TSs for the ring opening of perfluoro-3-methylcyclobutene 13 . The values in the parentheses are for the inward opening TSs

\begin{tabular}{lllll}
\hline$\pi_{\mathrm{C} 1 \mathrm{C} 2} \rightarrow \sigma_{\mathrm{C} 3 \mathrm{C} 4}^{*}$ & $\pi_{\mathrm{C} 1 \mathrm{C} 4} \rightarrow \pi_{\mathrm{C} 2 \mathrm{C3}}$ & $\pi_{\mathrm{C} 2 \mathrm{C} 3} \rightarrow \pi_{\mathrm{C} 1 \mathrm{C} 4}$ & $\sigma_{\mathrm{C} 3 \mathrm{C} 4} \rightarrow \sigma_{\mathrm{C}-\mathrm{F}}^{*}$ & $I_{\mathrm{F} \rightarrow} \rightarrow \pi_{\mathrm{C} 1 \mathrm{C} 4 / \mathrm{C2C} 3}$ \\
$0(0)$ & $65(62)$ & $60(60)$ & $0(0)^{\mathrm{a}}$ & $76(77)^{\mathrm{b}}$
\end{tabular}

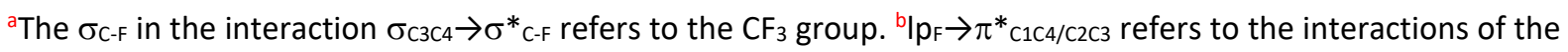
lone pairs of electrons of the fluorine atoms directly attached to $\mathrm{C} 3$ and $\mathrm{C} 4$. 


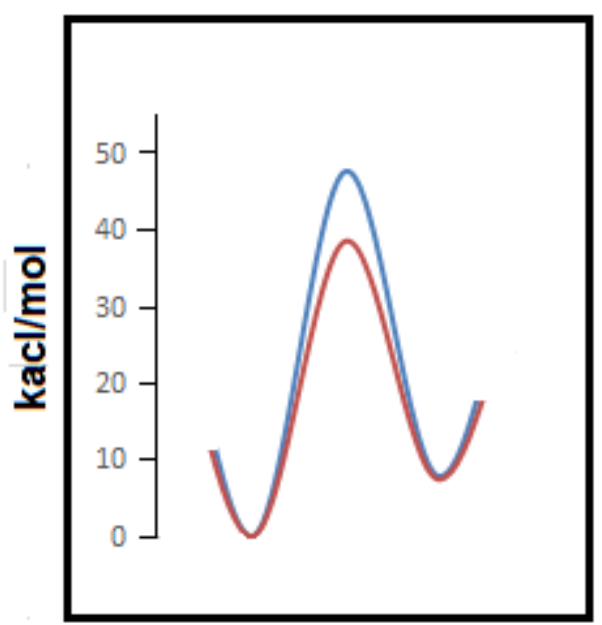

Reaction coordinate

Figure 3. Reaction profile for inward (solid red line) and outward (solid blue line) ring openings in perfluoro-3methylcyclobutene at the MP2/cc-pVTZ level of theory

The relevant NBO interactions are collected in Table 6 . The absence of $\pi_{\mathrm{C} 1 \mathrm{C2}} \rightarrow \sigma^{*}{ }_{\mathrm{c} 3 \mathrm{c} 4}$ interaction, and presence of $\pi_{\mathrm{C} 1 \mathrm{C}_{4}} \rightarrow \pi^{*}{ }_{\mathrm{C} 2 \mathrm{C3}}$ and $\pi_{\mathrm{C} 2 \mathrm{C3}} \rightarrow \pi^{*}{ }_{\mathrm{C} 1 \mathrm{C} 4}$ interactions clearly demonstrates that the TS structure is heavily advanced and product-like in both the modes of ring opening. The $\sigma_{\mathrm{c} 3 c 4}$ bond is completely broken and, hence, its interaction with $\sigma_{c-F}$ in the $\mathrm{CF}_{3}$ group is completely absent. The $\mathrm{F}$ atoms directly bonded to the ring play the key role and the interactions of their lone pairs of electrons with the largely developed $\pi$ bonds between $\mathrm{C} 1$ and $\mathrm{C} 4$, and $\mathrm{C} 2$ and $\mathrm{C} 3$ control the torquoselectivity. This differential interaction, however, is marginal and in favor of inward rotation of the $\mathrm{CF}_{3}$ group by only $1.0 \mathrm{kcal} / \mathrm{mol}$. The profiles for outward and inward opening reactions are shown in Figure 3.

Conclusions. The torquoselectivity of ring opening of substituted cyclobutenes and oxetenes is a consequence of the NBO interactions of the breaking ring bond with the substituent orbitals. The ring opening (outward or inward) that has larger interaction constitutes the preferred mode. The experimental torquoselectivity, if otherwise, is a likely consequence of secondary reactions, specifically equilibration by reaction reversal, while honouring the relative enthalpic stabilities of the ring opened products.

The conformational profile of the substituent also impacts the torquoselectivity and, hence, it must be taken into consideration in any comprehensive treatment of the subject. ${ }^{15}$ Conformational issues arise because the effective NBO interactions are largely antiperiplanar interactions and, hence, the relative orientation of the cleaving ring bond with the substituent bond is paramount.

\section{ASSOCIATED CONTENT}

\section{Supporting Information}


Supporting Information (SI) available: Cartesian coordinates of the optimized substrates and TS structures, Gibbs' free energies of the ground and TS structures, Imaginary Frequencies of the TS structures (34 pages)

\section{ORCID}

Veejendra K. Yadav: 0000-0001-8294-0677

\section{ACKNOWLEDGEMENTS}

The author acknowledges allocation of time on HPC series of supercomputers by the Computer Centre, Indian Institute of Technology Kanpur, and Dr. Dasari L. V. K. Prasad for fruitful discussions.

\section{REFERENCES}

1. R. B. Woodward, R. Hoffmann, Stereochemistry of Electrocyclic Reactions, J. Am. Chem. Soc. 1965, 87, 395-397.

2. (a) W. Kirmse, N. G. Rondan, K. N Houk, Stereoselective substituent effects on conrotatory electrocyclic reactions of cyclobutenes, J. Am. Chem. Soc. 1984, 106, 7989-7991. (b) N. G. Rondan, K. N. Houk, Theory of stereoselection in conrotatory electrocyclic reactions of substituted cyclobutenes, J. Am. Chem. Soc. 1985, 107, 2099-2111. (c) K. Rudolf, D. C. Spellmeyer, K. N. Houk, Prediction and experimental verification of the stereoselective electrocyclization of 3-formylcyclobutene, J. Org. Chem. 1987, 52, 3708-3710. (d) K. N. Houk, D. C. Spellmeyer, C. W. Jefford, C. G. Rimbault, Y. Wang, R. D. Miller, Electronic control of the stereoselectivities of electrocyclic reactions of cyclobutenes against incredible steric odds, J. Org. Chem. 1988, 53, 2125-2127. (e) C. W. Jefford, G. Bernardinelli, Y. Wang, D. C. Spellmeyer, A. Buda, K. N. Houk, Torquoselectivity in the electrocyclic conversion of benzocyclobutenes to o-xylylenes, J. Am. Chem. Soc. 1992, 114, 1157-1165. (f) S. Niwayama, K. N. Houk, Lewis acid reversal of the torquoselectivity of the electrocyclic ring opening of 3-acetylcyclobutene, Tetrahedron Lett. 1993, 34, 1251-1254. (g) K. Nakamura, K. N. Houk, Substituent Effects on Torquoselectivity. Computational Investigations of the Thermal Ring Openings of Cyclobutenes Fused to Substituted Cyclohexenes, J. Org. Chem. 1995, 60, 686-691. (h) S. Niwayama, Y. Wang, K. N. Houk, The torquoselectivity of electrocyclic reactions of 3-donor-3-acceptor-substituted cyclobutenes, Tetrahedron Lett. 1995, 36, 6201-6204. (i) S. Niwayama, A. K. Kallel, D. C. Spellmeyer, C. Sheu, K. N. Houk, Substituent Effects on Rates and Stereoselectivities of Conrotatory Electrocyclic Reactions of Cyclobutenes. A Theoretical Study, J. Org. Chem. 1996, 61, 2813-2825.

3. M. Murakami, T. Miyamoto, Y. Ito, A Silyl Substituent Can Dictate a Concerted Electrocyclic Pathway: Inward Torquoselectivity in the Ring Opening of 3-Silyl-1-cyclobutene, Angew. Chem., Int. Ed. 2001, 40, 189-190.

4. The frequency calculation for the TS structures could not be achieved at the MP2/cc-pVTZ level.

5. P. S. Lee, X. Zhang, K. N. Houk, Origins of Inward Torquoselectivity by Silyl Groups and Other $\sigma$-Acceptors in Electrocyclic Reactions of Cyclobutenes, J. Am. Chem. Soc. 2003, 125, 5072-5079. 
6. J. E. Barquera-Lozada, Torquoselectivity in Cyclobutene Ring Openings and the Interatomic Interactions That Control Them, J. Phys. Chem. A 2016, 120, 8450-8460.

7. (a) W. R. Dolbier, Jr, T. A. Gray, J. J. Keaffaber, L. Celewicz, H. Koroniak, Kinetic and Thermodynamic Effects in the Thermal Electrocyclic Ring-Openings of 3-Fluorocyclobutene, 3,3-Difluorocyclobutene, and 3-(Trifluoromethyl)cyclobutene, J. Am. Chem. Soc. 1990, 112, 363-367. (b) W. R. Dolbier, Jr, H. Koroniak, K. N. Houk, C. Sheu, Electronic Control of Stereoselectivities of Electrocyclic Reactions of Cyclobutenes: A Triumph of Theory in the Prediction of Organic Reactions, Acc. Chem. Res., 1996, 29, 471-477.

8. K. Aikawa, Y. Hioki, N. Shimizu, K. Mikami, Catalytic Asymmetric Synthesis of Stable Oxetenes via Lewis Acid-Promoted [2 + 2] Cycloaddition, J. Am. Chem. Soc. 2011, 133, 20092-20095.

9. K. Aikawa, N. Shimizu, K. Honda, Y. Hioki, K. Mikami, Effect of the trifluoromethyl group on torquoselectivity in the $4 \pi$ ring-opening reaction of oxetenes: stereoselective synthesis of tetrasubstituted olefins, Chem. Sci. 2014, 5, 410-415.

10. K. Honda, S. A. Lopez, K. N. Houk, K. Mikami, Mono-, Di-, and Trifluoroalkyl Substituent Effects on the Torquoselectivities of Cyclobutene and Oxetene Electrocyclic Ring Openings, J. Org. Chem. 2015, 80, 11768-11772. The publication concludes, "The torquoselectivities are thus controlled by a competition of $\sigma_{\mathrm{CO}} \rightarrow \sigma_{\mathrm{CF}} *$ effect and unfavorable closed-shell repulsions. Our calculations suggest that 2difluoromethyloxetenes prefer inward rotation because the favorable $\sigma_{\mathrm{CO}} \rightarrow \sigma_{\mathrm{CF}} *$ orbital effect outweighs closed-shell repulsions in the transition state."

11. P. Deslongchamps, Stereoelectronic Effects in Organic Chemistry, Pergamon Press, 1983.

12. W. R. Dolbier, H. Koroniak, D. J. Burton, P. Heinze, The electrocyclic interconversion of perfluoro-3methylcyclubutene with Z- and E-perfluro-1,3-pentadiene, Tetrahedron Lett. 1986, 27, 4387-4390.

13. M. J. Frisch, G. W. Trucks, H. B. Schlegel, G. E. Scuseria, M. A. Robb, J. R. Cheeseman, G. Scalmani, V. Barone, B. Mennucci, G. A. Petersson, H. Nakatsuji, M. Caricato, X. Li, H. P. Hratchian, A. F. Izmaylov, J. Bloino, G. Zheng, J. L. Sonnenberg, M. Hada, M. Ehara, K. Toyota, R. Fukuda, J. Hasegawa, M. Ishida, T. Nakajima, Y. Honda, O. Kitao, H. Nakai, T. Vreven, J. A. Montgomery Jr., J. E. Peralta, F. Ogliaro, M. Bearpark, J. J. Heyd, E. Brothers, K. N. Kudin, V. N. Staroverov, T. Keith, R. Kobayashi, J. Normand, K. Raghavachari, A. Rendell, J. C. Burant, S. S. Iyengar, J. Tomasi, M. Cossi, N. Rega, J. M. Millam, M. Klene, J. E. Knox, J. B. Cross, V. Bakken, C. Adamo, J. Jaramillo, R. Gomperts, R. E. Stratmann, O. Yazyev, A. J. Austin, R. Cammi, C. Pomelli, J. W. Ochterski, R. L. Martin, K. Morokuma, V. G. Zakrzewski, G. A. Voth, P. Salvador, J. J. Dannenberg, S. Dapprich, A. D. Daniels, O. Farkas, J. B. Foresman, J. V. Ortiz, J. Cioslowski, D. J. Fox, Gaussian 09, revision C.01, Gaussian, Inc., Wallingford, CT 2009.

14. J. A. Berson, The overlap component of the stereoelectronic factor. Remote control of stereogenicity transfer through the anisotropic influence of a ring, Acc. Chem. Res. 1991, 24, 215-222.

15. For a brief mention of conformational effect arising from geminal ethyl versus methyl groups, see: $E$. A., Kallel, Y. Wang, D. C. Spellmeyer, K. N. Houk, Electrocyclic ring openings of dialkylcyclobutenes: anomalies explained, J. Am. Chem. Soc. 1990, 112, 6759-6763. The inward rotation of the ethyl group was considered to give rise to more favorable gauche interactions than the methyl group. 